\title{
Phosphorus Removal Capability of Aspergillus Terreus and Bacillus Subtilis from Nigeria's Agbaja Iron Ore
}

\author{
C.N. Anyakwo ${ }^{1}$ and O.W. Obot ${ }^{2}$ \\ ${ }^{1}$ Department of Metallurgical and Materials Engineering, Federal University of Technology, \\ Owerri, Nigeria. Email: charlesanyakwo@yahoo.com \\ ${ }^{2}$ Department of Mechanical Engineering, Faculty of Engineering, University of Uyo, Nigeria. \\ Email: obotowo2009@gmail.com
}

\begin{abstract}
Comparative phosphorus removal capability of a microbial fungus-Aspergillus terreus and a bacterium-Bacillus subtilis from Nigeria's Agbaja iron ore was investigated. Manual crushing and sieving of the iron ore in Shital Test Kits produced 5 grain size distributions namely: $\geq 1.0 \mathrm{~mm}, 1.0 \mathrm{~mm} / 0.50 \mathrm{~mm}, 0.50 \mathrm{~mm} / 0.25 \mathrm{~mm}, 0.25 \mathrm{~mm} / 0.125 \mathrm{~mm}, 0.125 \mathrm{~mm} / 0.00 \mathrm{~mm}$, from which the first and last grain sizes were excluded from the experiment on technical grounds. Then $1 \mathrm{~g}$ of each of the remaining 3 grain sizes was carefully weighed for each set of experiment. Culturing and subsequent inoculation of the microbes (which are native to the iron ore) in conical flasks containing sterilized, weighed iron ore samples in $100 \mathrm{ml}$ of equally sterilized malt extract and nutrient broths were left to stand for 7 weeks in the laboratory. At weekly interval, the samples were removed, treated through series of chemical reactions to obtain ammonium phosphomolybdate precipitate which was back-titrated with $0.1 \mathrm{~N}-\mathrm{HCl}$ to determine the amount of phosphorus left in samples and consequently, the amount removed. The research found out Aspergillus terreus and Bacillus subtilis have separately and successfully removed phosphorusa deleterious non-metalic inclusion from Nigeria's Agbaja iron ore, which previously defiled all attempts at phosphorous removal and beneficiation techniques. However their ability at phosphorus removal was promising and varied with the grain sizes of ore. Across all grain sizes used, 58\% and 66\% phosphorus was removed in 7 weeks, respectively by the two microbes. It was also obvious that the capacity of the microbes in removing phosphorus was seriously hampered by a decline in activity as indicated by the reduction in microbial population in the microcosm. For B. subtilis the density of viable cells increased from an initial load $3.4 \times 10^{5}$ $c f u / m l$, at the beginning of experiment, to $2.2 \times 10^{7}$ in 2 weeks but later declined to $0.9 \times 10^{6}$ $\mathrm{cfu} / \mathrm{ml}$ at the end of 7 weeks. For A. terreus the initial biomass weight of $1 \mathrm{~g}$ inoculated increased to $1.993 \mathrm{~g}$ dry weight within 3 weeks but later decreased to $0.910 \mathrm{~g}$ dry weight in the $7^{\text {th }}$ week. The reduction in microbial activity may be attributed to antimicrobial components of the ore, pyrite, and other heavy metals which may have affected the phosphorus uptake from ore. Our findings have confirmed the stronger phosphorus removal capability of B. subtilis under
\end{abstract}


submerged culture technique. It is however suggestive that A. terreus may perform optimally if the submerged medium is constantly aerated.

Key words: Microbes, Culture, Crushing, Digestion, Broth, Furnace, Biodegradation

\section{INTRODUCTION}

The Nigeria's Agbaja iron ore reserve having about 47.5\%Fe [1] remains till date the largest known in the country but had long been abandoned due to its very high phosphorus content variously estimated at about $0.76-0.89 \mathrm{Wt} \%[2,6]$. The mineralogy of Agbaja iron ore revealed abundant goethite with minute magnetite. Hematite, pyrite, siderite and chlorite were also identified [3]. A successful removal of phosphorus to a metallurgical acceptable level therefore, from the over 1.2 billion tons ore reserve [4] can mean an economic boom for the country with quite substantial multiplier effects in the areas of job creation and downstream sectors of iron and steel industry.

Phosphorus is a deleterious inclusion that is responsible for steel brittleness causing it to fracture and snap at very low stress values, also associated with phosphorus are the problems of strong primary segregation during solidification of castings and the formation of high phosphorus brittle streaks between metal grains thereby impeding plastic deformation. Thus, for high quality steels, the phosphorus acceptable level is in the range $0.010-0.020 \mathrm{Wt} \%$ or even less [5].

A flurry of research activities into the removal of phosphorus from the Nigeria's Agbaja iron ore commenced in the eighties. Researchers predominantly applied the conventional froth flotation technique for the removal of phosphorus but failed because the phosphorus is not associated with the gangue but is in bonding with the iron [6,7]. An evolving trend in mineral processing currently gaining popularity is the use of microbes and the works of researchers in this regards are well documented. Using the bacterium Burkholderia caribensis isolated from a Brazilian high-phosphorus iron ore, Delvasto et al [8] were able to mobilize between $5-20 \%$ of the phosphorus originally contained in the ore in 21 days of treatment in shake-flask cultures. Similarly in another work, Aspergillus niger also isolated from the same Brazilian highphosphorus ore was employed to remove phosphorus from the same ore and again in 21 days between 13.8-33.2\% was achieved [9]. In the beneficiation of iron ore slime Aspergillus niger and Bacillus circulans were able to remove alumina with B. circulans and A. niger showing 39 and 38 percents, respectively of alumina removal after 6 and 15 days, respectively of in situ leaching at $10 \%$ pulp density. Also a culture filtrate leaching with $A$. niger removed $20 \%$ alumina at $2 \%$ pulp density with 13 day old culture filtrate. $B$. circulans was more efficient than A. niger for selective removal of alumina [10]. Earlier on A. niger isolated from Nigeria's Agbaja iron ore was used to mobilize phosphorus from the same ore and in 49 days of leaching, $81 \%, 63 \%$ and 68\% efficiencies for Mesh 5, Mesh 100 and Mesh 250 grain sizes, respectively were achieved [11]. In this work, a microbial leaching approach has been adopted for comparative investigations of the phosphorus removal capabilities of Aspergillus terreus and 
Bacillus subtilis on Nigeria's Agbaja iron ore. This approach is economical, environmental friendly and has an uncommon potential for easy incorporation into existing iron and steel making technologies.

\section{MATERIALS AND METHODS}

The main material for this research, iron ore, was obtained from Agbaja area near Lokoja in Kogi State of Nigeria. A sizable piece of the iron ore was crushed in the laboratory and a standard laboratory Shital Test Kits mesh was employed to sieve the grains obtained into $\geq 1.00 \mathrm{~mm}$, $1.00 \mathrm{~mm} / 0.50 \mathrm{~mm}, 0.50 \mathrm{~mm} / 0.25 \mathrm{~mm}, 0.25 \mathrm{~mm} / 0.125 \mathrm{~mm}$ and $0.125 \mathrm{~mm} / 0.00 \mathrm{~mm}$ grain size distributions. The first and last grain sizes were not used because of handling(large pieces and dust, respectively). The microbes for the experiment were those native to the iron ore environment and were obtained from the ore samples. In order to generate sufficient amount of microbes necessary to cause degradation of phosphorus in the iron ore, the microbes were initially cultured in mineral oil medium (MOM).

$10 \mathrm{~g}$ of each of the grain sizes of iron ore was serially diluted up to $10^{-6}(6$ times by 10 folds dilution). Each final dilution was taken to seed sterile petri dishes and about $20 \mathrm{ml}$ of MOM at 45 ${ }^{\circ} \mathrm{C}$ was added to each seeded petri dish, swirled and allowed to set and thereafter incubated for 14 days. Some petri dishes were incubated aerobically and while others anaerobically. Bacteria and fungi colonies were counted and recorded in colony forming unit per milli-litre $(\mathrm{cfu} / \mathrm{ml})$. The fungi colonies were sub-cultured into Sabouard dextrose agar (SDA) and the bacterial colonies into Nutrient agar (NA). The growth colonies were characterized and identified using standard manuals for fungal and bacterial identification $[12,13]$. The isolates were Aspergillus terreus and Bacillus subtilis.

In order to allow biodegradation of phosphorus in iron ore using the test organisms to take place, $100 \mathrm{ml}$ of malt extract broth (MEB) was prepared and dispensed into $250 \mathrm{ml}$ conical flasks. Also, $100 \mathrm{ml}$ of nutrient broth (NB) was prepared and similarly dispensed into $250 \mathrm{ml}$ conical flasks. The conical flasks were sterilized using autoclave at $121{ }^{\circ} \mathrm{C}$ at $10 \mathrm{psi}$. On cooling, $1 \mathrm{~g}$ of an already sterilized iron ore from the sample bottles was accurately weighed and mixed with each of the $100 \mathrm{ml}$ MEB and NB media earlier dispensed into the $250 \mathrm{ml}$ flasks. A loopful of $A$. terreus spores from the culture in petri dishes was used to inoculate each of the MEB, and $1 \mathrm{ml}$ of the $B$. subtilis broth culture was used to inoculate each of the NB aseptically. Some conical flasks of each of the media were not inoculated with the test organisms, and they served as the control.

Finally, a batch of 12 conical flasks representing each of the 3 mesh sizes from both MEB and NB media and their controls were removed for phosphorus analysis periodically beginning from week 1 to the 7th, when the stock was exhausted. The samples were treated through series of standard chemical reactions [14] to obtain the data presented in Figs.1-5. 


\section{RESULTS AND DISCUSSION}

A comparison of the capabilities of $A$. terreus and B. subtilis at removing phosphorus from Nigeria's Agbaja iron ore in $1.0 \mathrm{~mm} / 0.50 \mathrm{~mm}$ grain size for the period of 7 weeks is presented in Fig.1. In the first instance, B. subtilis (a faster self-generating microbe) removed more phosphorus from Week 1 till about Week 5 and thereafter slowed down from Week 6 to Week 7. During this time its population degenerated from $1.4 \times 10^{7} \mathrm{cfu} / \mathrm{ml}$ to $0.9 \times 10^{6} \mathrm{cfu} / \mathrm{ml}$. A. terreus, a slower self-generating fungus population rose from $0.692 \mathrm{~g}$ dry weight in Week 1 to a peak of $2.786 \mathrm{~g}$ dry weight in Week 3 and quickly dropped to $0.963 \mathrm{~g}$ dry weight in Week 7 averaging out in stagnation. One possible explanation for this pattern is that the microbes having actively degraded phosphorus in the ore samples from the $1^{\text {st }}$ week were also actively dying of toxicity due to biodegradation wastes and this resulted in their diminished population in the microcosm.

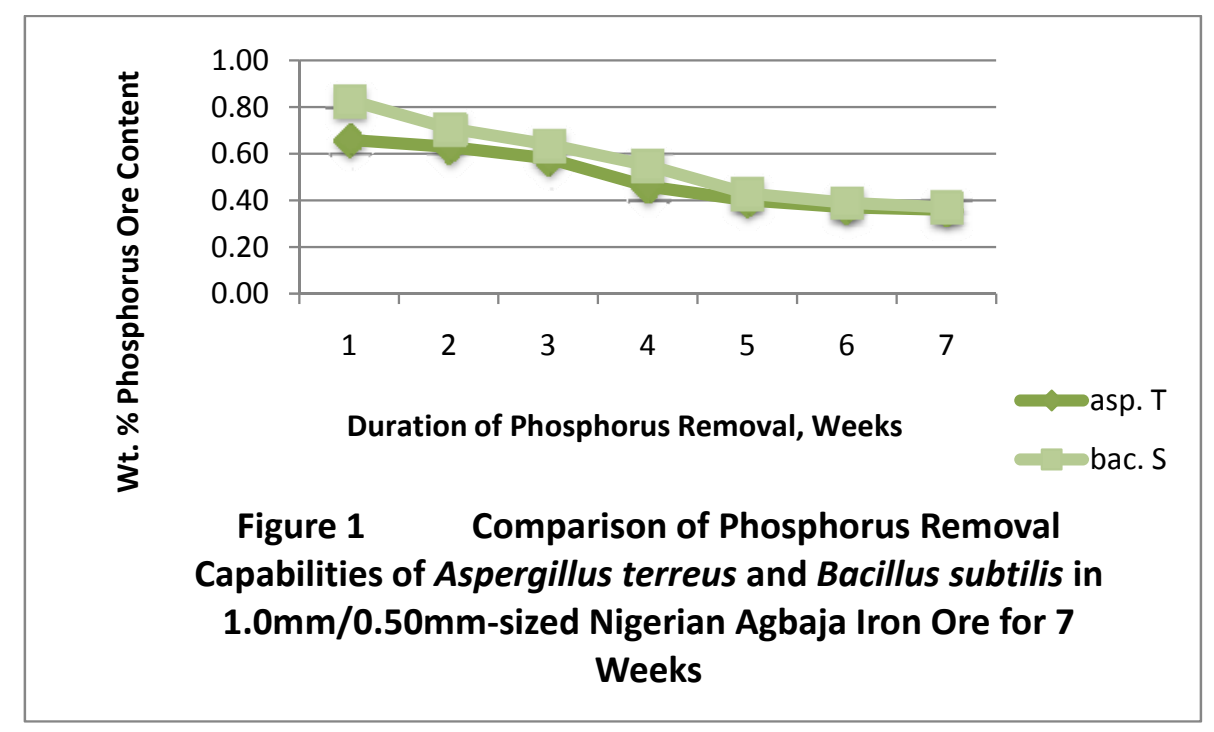

In Fig.2 for instance, the potential of $B$. subtilis to remove phosphorus from $0.50 \mathrm{~mm} / 0.25 \mathrm{~mm}$ sized Nigerian Agbaja iron ore was higher than that of $A$. terreus and dominated effectively till midway of Weeks 3 and 4 . This period witnessed a population of $1.92 \times 10^{7}-5.6 \times 10^{6} \mathrm{cfu} / \mathrm{ml}$ which continued to diminish to $1.0 \times 10^{6} \mathrm{cfu} / \mathrm{ml}$ at Week 7. During this period, the microbial count for A. terreus grew from $0.726-1.964 \mathrm{~g}$ dry weight and then went on to remove more phosphorus till Week 7. 


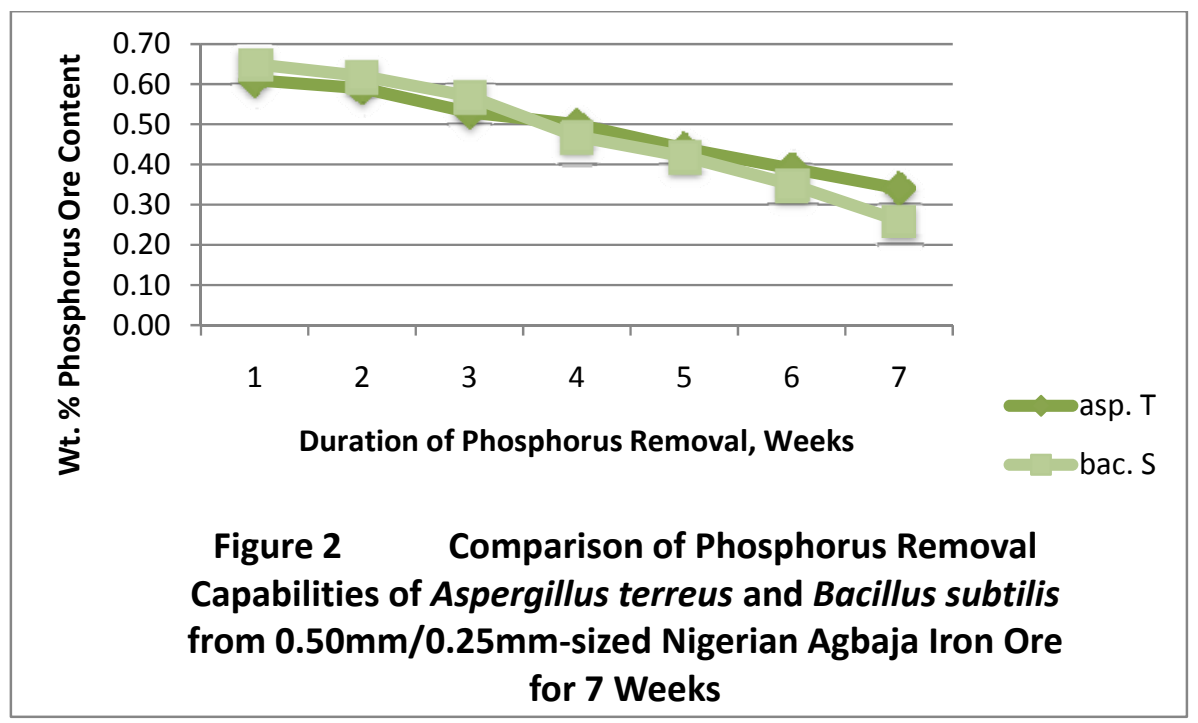

In Fig.3, A. terreus in Week 1 removed more phosphorus than B. subtilis and this trend was sustained till start of Week 3. The microbial count of this fungus over this period rose from $0.686 \mathrm{~g}$ dry weight to $1.993 \mathrm{~g}$ dry weight while that of $B$. subtilis dropped $2.10 \times 10^{7} \mathrm{cfu} / \mathrm{ml}$ to $6.2 \times 10^{6} \mathrm{cfu} / \mathrm{ml}$. Between Week 3 and Week 4 the overall performance of both microbes seems to have stagnated during which time their average count stood at $1.755 \mathrm{~g}$ dry weight and $5.0 \times 10^{6}$ $\mathrm{cfu} / \mathrm{ml}$, respectively. From end of Week 4 the population of the bacterium dropped seriously from $3.7 \times 10^{6} \mathrm{cfu} / \mathrm{ml}$ to $1.0 \times 10^{6} \mathrm{cfu} / \mathrm{ml}$ in Week 7 while that of fungus increased initially from $1.516 \mathrm{~g}$ dry weight to $1.168 \mathrm{~g}$ dry weight in Week 5 and then nose-dived to $0.910 \mathrm{~g}$ dry weight in Week 7.

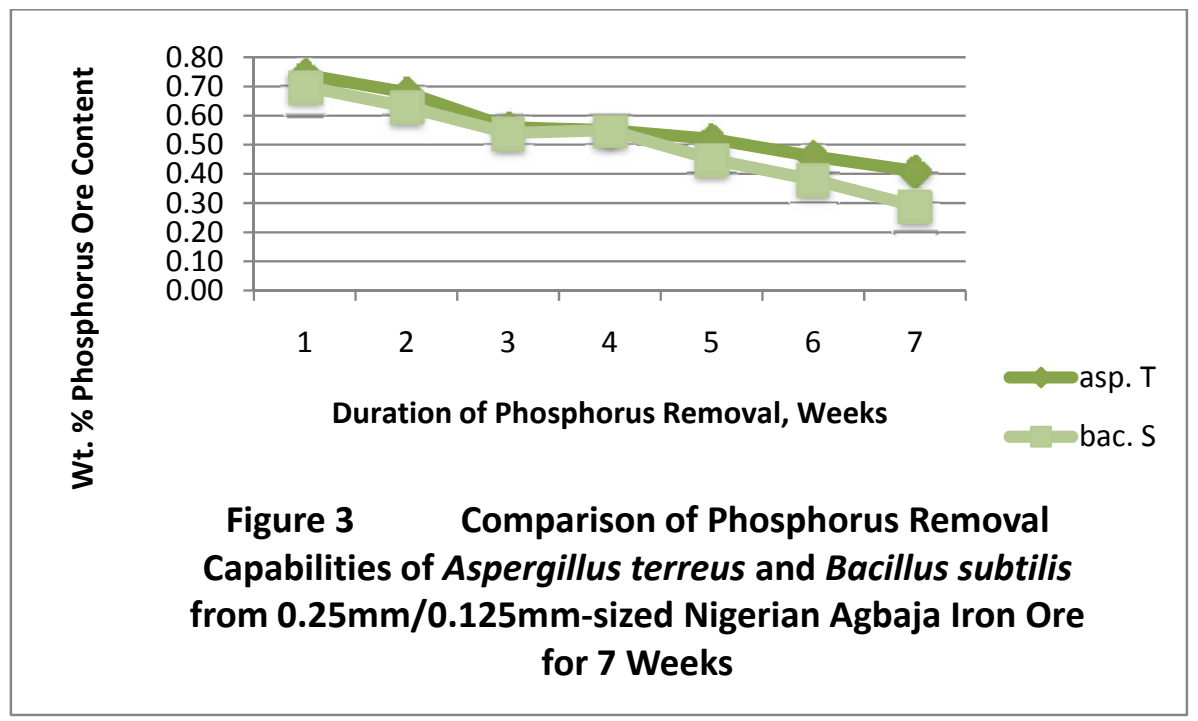


The views separately presented in Figs.1-3 are better evaluated in Fig. 4 where the three averages are brought together for comparison. From Week 1 to midway of Weeks 4 and 5, Bacillus subtilis removed more phosphorus than $A$. terreus. This clearly shows that while about $64 \%$ of the duration of experimentation was dominated by B. subtilis in removing phosphorus, $A$. terreus only dominated a mere $36 \%$.

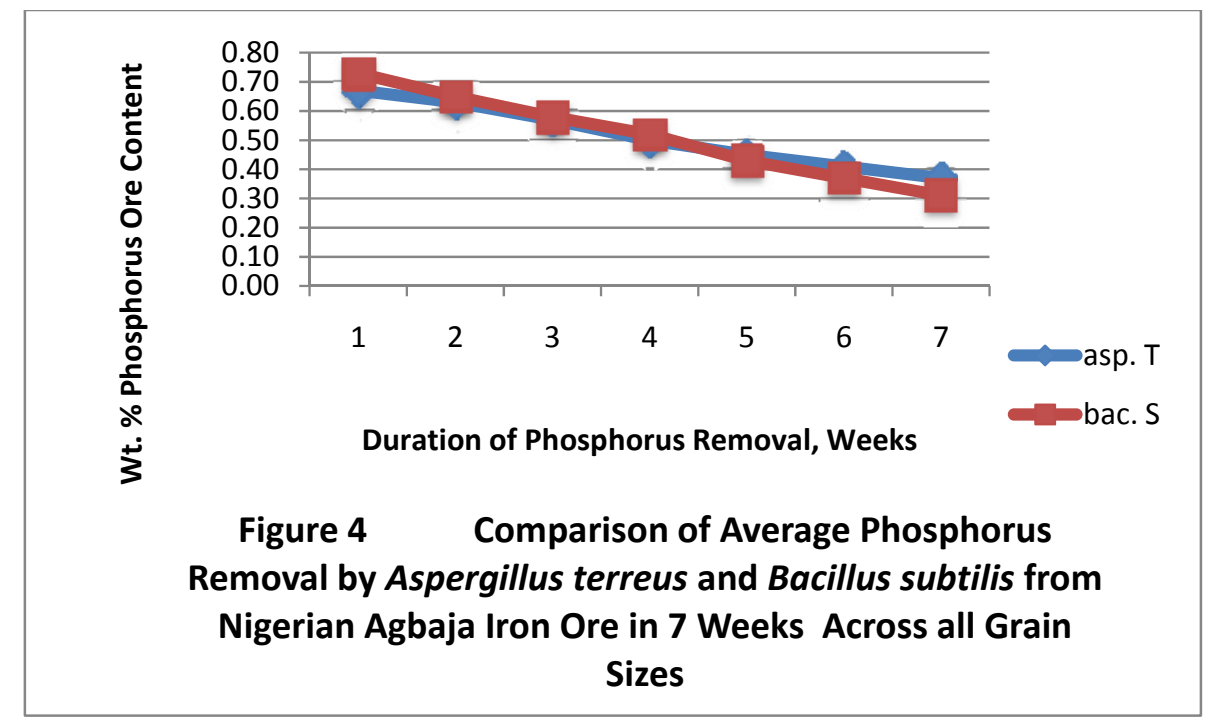

The average percentage of phosphorus removed by A. terreus and B. subtilis can still better be evaluated when presented as in Fig.5. In the first week, $24 \%$ and $19 \%$ removal was achieved, respectively by both microbes. At the end of the experiment duration, $58 \%$ and $66 \%$ respectively, were recorded for the microbes with $B$. subtilis out-performing the other. Although both microorganisms actively removed phosphorus from the ore samples even, when ore contained pyrite[15] being an effective antimicrobial substance. It is also necessary to note that the metabolic activity of $A$. terreus an obligate aerobe may have been affected by the excessively moistened or reduced substrate of the submerged culture technique. Under this condition active contact with the settled ore samples at the bottom of the flask may be hindered despite their ability to produce hyphae. On the other hand, B. subtilis generally a micro-aerophilic bacterium whose metabolic activities are less affected by the submerged culture technique employed in this research performed better. Although a technique of periodic manual-shaking of the conical flasks and content was adopted as a means of ensuring a more intimate interaction in the system, it probably did not do much in altering the above observed microbial characteristics. 


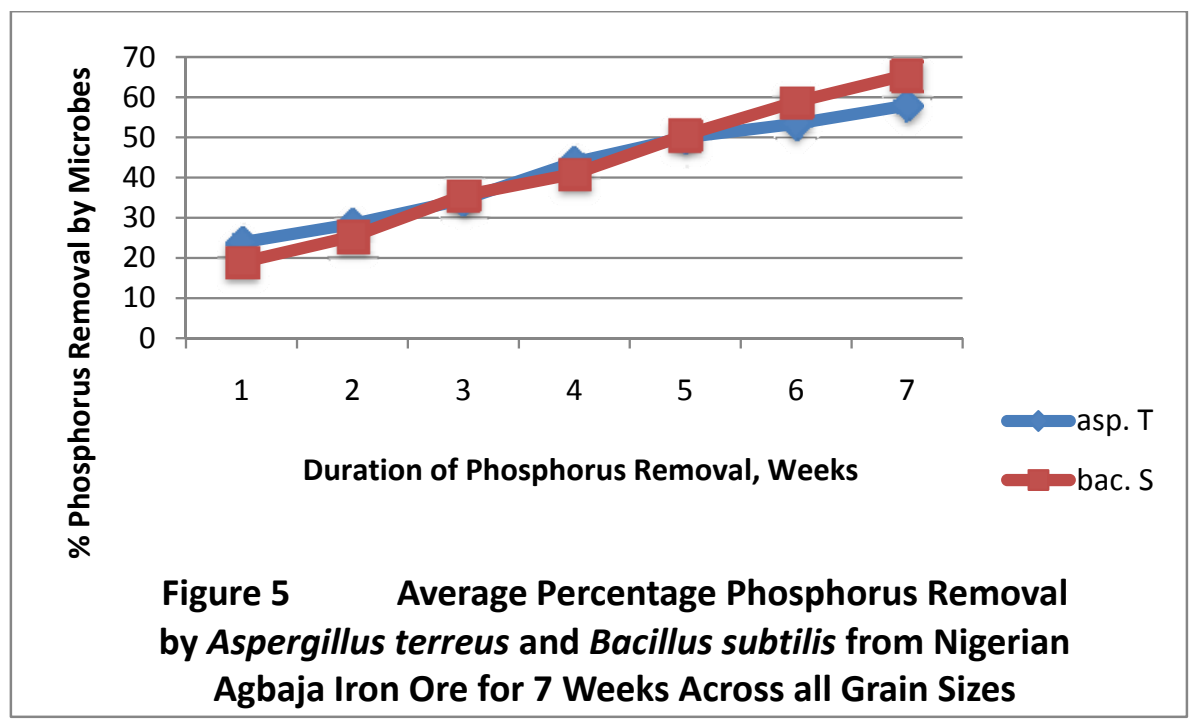

\section{CONCLUSION}

Aspergillus terreus and Bacillus subtilis both have the capability to successfully remove phosphorus from Nigeria's Agbaja iron ore. The result of this research shows that 58 and 66 percents removal, respectively, were achieved in 7 weeks of experimentation when $1 \mathrm{~g}$ of ore samples were subjected in $100 \mathrm{ml}$ of media and inoculated with the microbes. A better phosphorus removal capability demonstrated by Bacillus subtilis is natural because they are not affected by the reduced nature of the test substrate. It is suggested that Aspergillus terreus may perform optimally if the submerged medium is constantly aerated. However, these findings necessitate further investigation.

\section{ACKNOWLEDGEMENT}

Particularly deserving great thanks are the staff and Heads of Departments of Microbiology and Chemical Engineering of University of Uyo, Akwa Ibom State. Few names will not fail to be mentioned and I wish to thank my Supervisor, Engr. (Dr.) C. N. Anyakwo who, actually not only conceived the work and provided the experimental strategies stage by stage, but also, brought his knowledge and expertise to bear on the entire work. Engr. Peter Asangausung, the Senior Technologist in-charge of the Chemical Engineering Laboratory where the bulk of this work was done, for his resourcefulness, keen interest and constant prayers; Dr. A. O. Ano of the Nigerian Root Crops Research Institute, Umuahia, Abia state, whose elastic patience limit was over stretched many times in an unprecedented manner by my over-keeping borrowed equipment worth millions of naira in order to complete this research. 


\section{REFERENCES}

1. Amadi, N. J., Odunaike, A. A and Marthur, G. P; Preliminary Bench Scale Beneficiation Studies with Three Lumps of Iron Ore Sample from Agbaja, Central Metallurgical Research and Development Institute, Jos, Nigeria, 1982.

2. Uwadiale, G. G. O. O, 1991, 'Electrolytic Coagulation and selective Flocculation of Agbaja Iron Ore', Journal of Mining and Geology Vol.27 No.1, 1991.

3. Uwadiale, G. G. O. O 'Beneficiation Studies of Agbaja Iron Ore', Ph.D thesis, University of Strathclyde, June 1984, 341pp.

4. Uwadiale, G. G. O. O and Whewell, R. J; Effect of Temperature on Magnetizing Reduction of Agbaja Iron Ore, Metallurgical Transaction B, Vol. 19B, October 1988, pp 731735.

5. Kudrin, V., Steel Making, MIR Publishers, Moscow, 1985, pp 82-83.

6. Uwadiale, G. G. O. O. and Nwoke, M. A. U.; Beneficiation of Agbaja Iron Ore by Reduction Roasting- Magnetic Separation: Semi Pilot Plant Scale-up and Establishment of Residence Point of Phosphorus, National Steel Council, Metallurgical Research and Tests Division, Jos, Nigeria, June 1983.

7. Uwadiale, G. G. O. O. and Emeka, Okafor; Petrology of Agbaja Ironstone, National Steel Council, Metallurgical Research and Tests Division, Jos, Nigeria, October 1983.

8. Delvasto, P. et al, 2005. Exploring the possibilities of biological beneficiation of iron-ores: The phosphorus problem. In: Proceedings of the 15th Steelmaking Conference, 5 th Ironmaking Conference \& 1st Environment and Recycling Symposium IAS (CD-ROM). Argentinean Steelmaking Institute (IAS). San Nicolás, Buenos Aires, Argentina, November 7-10, 2005. pp 71-82.

9. Dephosphorisation of an Iron Ore by a Filamentous Fungus by Pedro Delvasto et al-Google Search- Windows Internet Explorer.

10. Pradhan, N. et al., 2006, "Beneficiation of Iron Ore Slime using Aspergillus niger and Bacillus circulans', Bioresource Technology 97: 15, P. 1876-1879

11. Anyakwo, C. N., Obot, O. W., 2008, “Phosphorus Removal from Nigeria's Agbaja Iron Ore by Aspergillus niger', International Research Journal in Engineering, Science \& Technology, Vol. 5 No. 1, pp 54-58.

12. Barnett, H. L., and Hunter, Barry B., 1987, "Illustrated Genera of Imperfect Fungi,', $4^{\text {th }}$ Edition, Macmillan Publishing coy, New York, Collier Macmillan Publishers, London.

13. Holt, John G., Krieg, Noel R., Sneath, Peter H. A., Stanley, James T., and Williams, Stanley T., 1994, "Bergy's Manual of Determinative Bacteriology," $9^{\text {th }}$ Edition, Lippincott Williams and Wilkins, Maryland, USA. pp. 559,562.

14. Jain S. K., (1982). An Introduction to Metallurgical Analysis: Chemical and Instrumental, India, New Delhi, Vikas Publishing House.

15. Uwadiale, G. G. O. O., "'Processing Nigerian Iron Ores’, National Steel Council, Metallurgical Research and Tests Division, Jos, Nigeria, July 1986. 